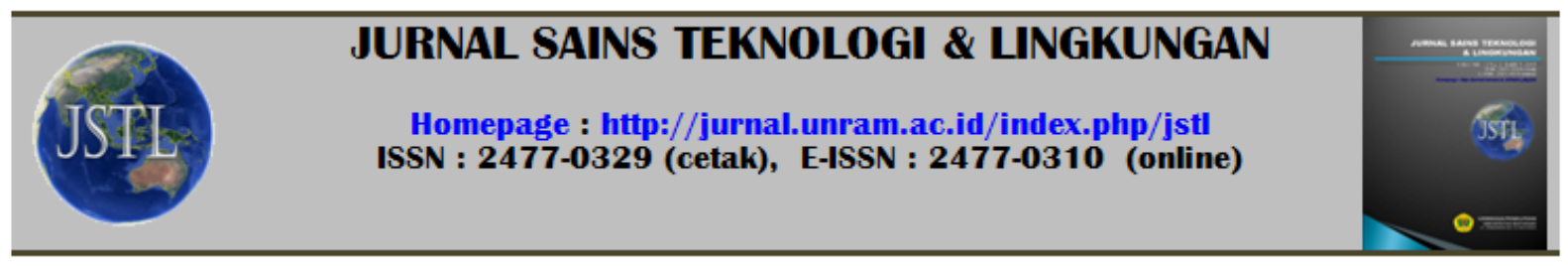

\title{
ASESMEN BALOK BETON BERTULANG DENGAN PENDEKATAN HASIL PENGUJIAN NDT DI LABORATORIUM
}

\begin{tabular}{|c|c|}
\hline Kata kunci : & Abstrak \\
\hline $\begin{array}{l}\text { Pengujian NDT, } \\
\text { cepat rambat } \\
\text { gelombang }(\mathrm{v}) \text {, } \\
\text { nilai pantul }(\mathrm{R}) \text {, } \\
\text { dan kekuatan sisa } \\
(\mathrm{KS}) \text {. }\end{array}$ & 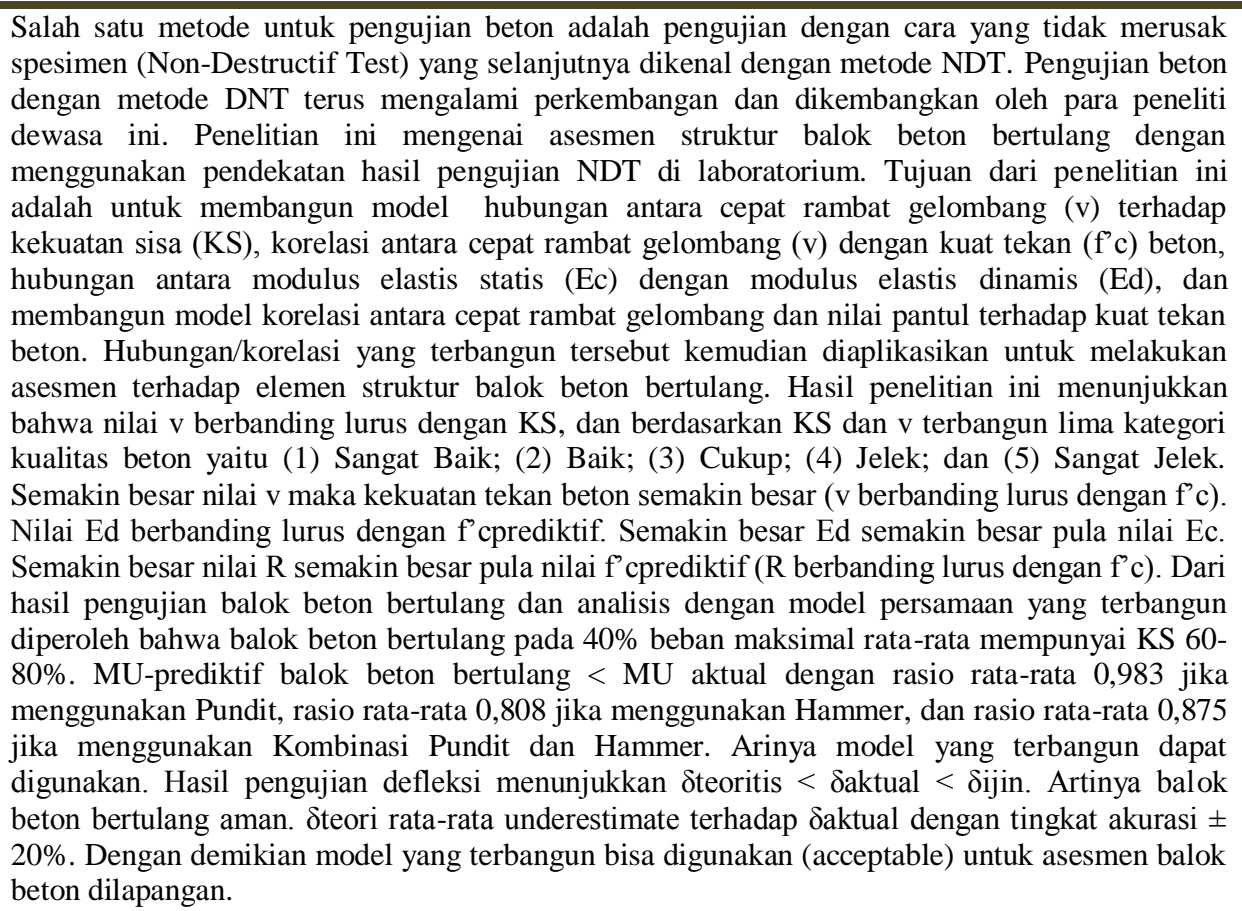 \\
\hline
\end{tabular}

Key words :
NDT, velocityve (v),
the value of
reflectance $(R)$, and
Compression
strength

Abstract

One method for testing concrete is non-destructive test (NDT). NDT is a way for testing that does not damage the specimen. Today DNT concrete testing methods has been develops and is still bieng developed by researchers. The research studies on the assessment of reinforced concrete beams using NDT test approach in laboratory. PUNDIT and Hammer is an equipment that can be used to determine the compressive strength and elastic modulus that does not damage the specimen. To get a valid result NDT equipment used needs to validation or verification of NDT results with the results of the testing standard methods. This study used three cylinder, twelve units cube of $20 \times 20$ and nine beams of 100x150x110. Before testing on beams performed a preliminary test on the specimen cube to build a model that will be applied to the beam. Results showed that the greater the value of $v$, the greater the compressive strength of concrete. The higher value of dinamic of $E d$, the higher of $f^{\prime} c$. The greather value of $E d$, the greather of static of modulus elasticity. The higher the R-value, the higher the value of $f^{\prime} c$. The relationship between the compressive strength $\left(f^{\prime} c\right)$ with a dynamic elastic modulus $(E d)$, and the relationship dynamic elastic modulus (Ed) with the static elastic modulus $(E c)$ is generated. By using the model in assessment of reinforced concrete beam specimen was obtained the results predicted ultimate moment $(\mathrm{Mu})$ of beams underestimate or smaller 0.983 towards $M u$ experiment/actual if $f^{\prime} c$ predicted based on the $v$-value. And underestimate 0.808 from $M u$ experiment/actual if $f^{\prime} c$ predicted based on the value of $R$. The prediction results of deflection, $\delta$ theory underestimate towards $\delta$ experiment/actual with accuracy $\pm 20 \%$ if $f^{\prime} c$ predicted based on $v$-value and $\delta$ theory, underestimate of $\delta$ experiment/actual if $f^{\prime} c$ predicted based on $R$-value with accuracy $\pm 20 \%$.

(C)2015 Universitas Mataram

$\triangle$ Alamat koresponden penulis: E-mail : emamardiana@ gmail.com 


\section{PENDAHULUAN}

Terdapat dua cara untuk mengetahui kondisi dari mutu beton tersebut yaitu dengan uji mutu beton dengan merusak spesimen (Destruktif) dan uji mutu beton tanpa merusak spesimen (Non-Destruktif). Dengan uji beton yang sifatnya merusak spesimen, mutu beton yang dihasilkan bersifat aktual berdasarkan kuat tekan di laboratorium sedangkan uji mutu beton yang sifatnya tidak merusak spesimen, mutu yang dihasilkan bersifat perkiraan/prediktif. Penggunaan kedua metode uji ini disesuaikan dengan kebutuhan, umumnya untuk struktur beton yang masih baru pembuatannya menggunakan "destruktif test" $(D T)$ tetapi untuk struktur beton yang masih aktif penggunaanya, metode uji yang tepat adalah "Non-destruktif test"(NDT) agar tidak mengganggu fungsi dari struktur beton tersebut.

Metode NDT Dalam beberapa tahun terakhir berkembang pesat, telah tersedia alat uji struktur beton yang dapat digunakan untuk penilaian struktur yang ada, namun masih belum ditetapkan untuk pemeriksaan secara rutin. Metode uji tidak merusak yang umum digunakan saat ini adalah dengan menggunakan hammer test, Ultrasonic Pulse VelocityPUNDIT, cavermeter, Resonant Frequency Test dan lain-lain. Tes $N D T$ juga sering berhubungan dengan kekuatan beton yang dibutuhkan oleh penyidik. Penekanan pada kekuatan beton timbul dari kenyataan bahwa sebagian besar cara kontrol durabilitas dan kinerja dalam pelaksanaannya mempengaruhi sifat kekuatan betonnya (Nash, a, \& Sadoon, 2005).

NDT mudah untuk diterapkan tetapi interpretasi dan analisis data lebih sulit. ada masalah dalam grafik kalibrasi yang disiapkan oleh produsen. Sebagai catatan bahwa penggunaan grafik kalibrasi yang dibuat oleh produsen alat NDT perlu di pertimbangkan, karena diagram itu di turunkan atas dasar pengujian beton dengan jenis dan ukuran agregat tertentu, bentuk benda uji yang tertentu dan kondisi tes tertentu (Lubis, 2003).

Untuk mensiasati problem tersebut atau agar hasil asesmen dengan alat $N D T$ di lapangan lebih akurat maka diperlukan informasi akurasi alat Hammer dan Pundit dengan pengujian aktual spesimen beton di laboratorium.

Tujuan utama penelitian adalah untuk membangun model korelasi dari bacaan peralatan NDT (Pundit dan Hammer) dengan dengan kuat tekan (f'c) dan Modulus elastisitas (E) serta melakukan asesmen keamanan struktur dengan tinjauan kapasitas penampang (ultimate limits state) dan lendutan/defleksi (serviceability limits state) pada elemen balok beton bertulang.

\section{METODOLOGI PENELITIAN}

\section{Lokasi Penelitian}

Penelitian ini adalah Penelitian Eksperimen yang dilaksanakan di Laboratorium Struktur dan Bahan Jurusan Teknik Sipil Fakultas Teknik Universitas Mataram.

\section{Alat dan Bahan}

Peralatan utama dalam penelitian ini adalah mesin uji tekan CTM (compression Testing Machine) merek Controls Milano, peralatan NDT test merek PUNDITplus buatan CNS FARNELL Inggris, hammer test merek Controls dan set mesin uji lentur balok ADVANTEST9.Sedangkan bahan penyusun beton yang digunakan berupa semen portlan tipe I dan bahan agregat (agregat halus dan agregat kasar) berasal dari Ijo Balit, Lombok Timur yang disediakan oleh PT. Utama Beton Perkasa. Untuk benda uji balok digunakan tulangan baja polos $\Phi 10 \mathrm{~mm}$ dan begel/sengkang $\Phi 6 \mathrm{~mm}$.

\section{Rancangan Campuran}

Sebelum dibuat campuran beton (mix design) terlebih dahulu dilakukan pemeriksaan bahan penyusun beton (agregat halus dan agregat kasar), pemeriksaan ini dimaksudkan untuk mengetahui spesifikasi bahan yang akan digunakan sebagai bahan penyusun beton antara lain : air, Semen Portland, agregat halus/pasir, dan agregat kasar/kerikil. Setelah mengetahui spesifikasi bahan yang meliputi; berat satuan agregat, modulus halus butir (MHB) agregat halus dan agregat kasar, kadar lumpur agregat halus dan berat jenis agergat, dibuat rancangan campuran beton seperti disajikan dalam tabel 1 berikut ini.

\begin{tabular}{l} 
Tabel 1. Rancangan Komposisi Campuran \\
\hline \begin{tabular}{|c|c|c|c|c|c|}
\hline$f \mathrm{c}(\mathrm{Mpa})$ & Fas & Semen $\left(\mathrm{kg} / \mathrm{m}^{3}\right)$ & Air $\left(\mathrm{kg} / \mathrm{m}^{3}\right)$ & Pasir $\left(\mathrm{kg} / \mathrm{m}^{3}\right)$ & Kerikil $\left(\mathrm{kg} / \mathrm{m}^{3}\right)$ \\
\hline 25 & 0,56 & 360 & 205 & 740 & 1110 \\
\hline 35 & 0,48 & 427 & 205 & 713 & 1070 \\
\hline 45 & 0,43 & 477 & 205 & 693 & 1040 \\
\hline
\end{tabular}
\end{tabular}

\section{Spesimen Uji}

Untuk mencapai tujuan yang diinginkan maka rancangan percobaan dibuat sedemikian rupa dengan memvariasikan kuat tekan beton dan besar pembebanan pada benda uji. Total benda uji yang diperlukan sejumlah 57 buah 
dengan rincian 9 buah silinder $\Phi 15 \mathrm{~cm}$ x $30 \mathrm{~cm}$, 45 Kubus $20 \times 20 \mathrm{~cm}$, dan 9 buah spesimen Balok dengan $b=10 \mathrm{~cm}, \mathrm{~h}=15 \mathrm{~cm}$ dan $\mathrm{p}=110 \mathrm{~cm}$, seperti ditunjukkan Gambar 3. berikut ini.

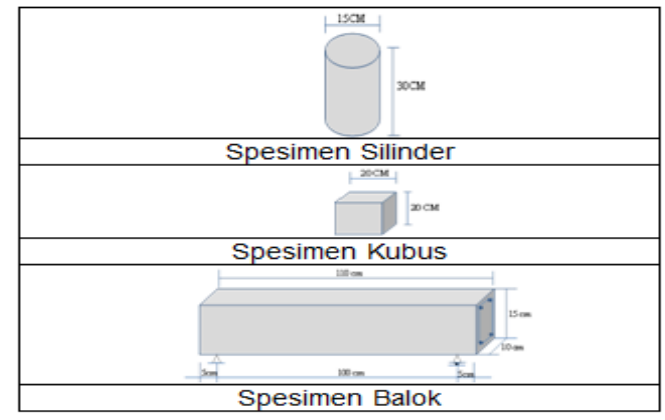

Gambar 3. Spesimen

\section{Uji Kombinasi Destruktif (DT) dengan Non Destructive Test (NDT)}

Pengujian ini bertujuan untuk membangun model yang nantinya diaplikasikan untuk asesmen balok beton bertulang. Untuk membangun model tersebut digunakan 9 buah kubus 20x20 cm masing-masing 3 buah kubus mutu beton $25 \mathrm{MPa}$, $35 \mathrm{MPa}$, dan $45 \mathrm{MPa}$. Pada setiap benda uji dalkukan Pengujian pembebanan dengan "compressive-testing mechine" pada setiap interval kenaikan beban ( $0 \% \mathrm{P}, 25 \% \mathrm{P}, 50 \% \mathrm{P}, 75 \% \mathrm{P}$ dan $100 \%$ /hancur) dilakukan pembacaan cepat rambat gelombang dengan alat PUNDIT dan nilai pantul dengan peralatan Hammer test. seperti ditunjukkan pada Gambar 4 berikut ini:

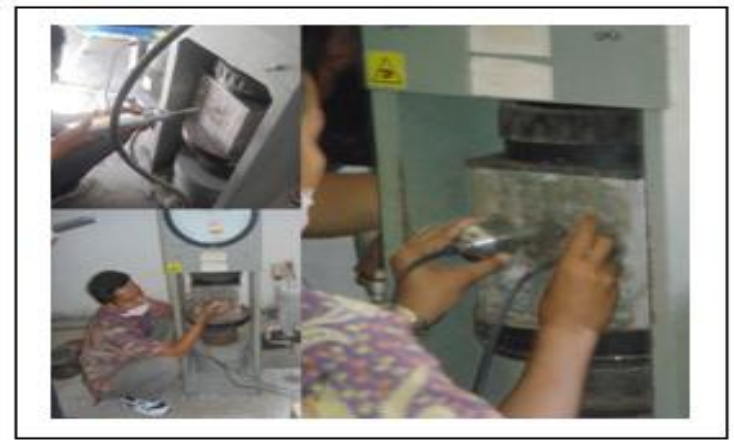

Gambar 4. Pengujian Combinasi $D T$ dan NDT

\section{Uji Lentur}

Pengujian elemen balok bertujuan sebagai perwakilan elemen struktur balok dilapangan. Pada pengujian ini akan diaplikasikan model yang terbentuk pada pengujian utama pada kubus beton untuk melihat kualitas balok dan tingkat keamanan elemen struktur berdasarkan Kapasitas Penampang (Ultimate Limits State) dan kontrol terhadap defleksi (Serveacibility Limits State), sebarapa besar rasio hasil penerapan model terhadap kondisi balok yang sebenarnya berdasarkan pembebanan sesungguhnya. Untuk tujuan ini 3 buah benda uji disiapkan untuk masing-masing beton $25 \mathrm{Mpa}$, 35 Mpa dan 45 Mpa.

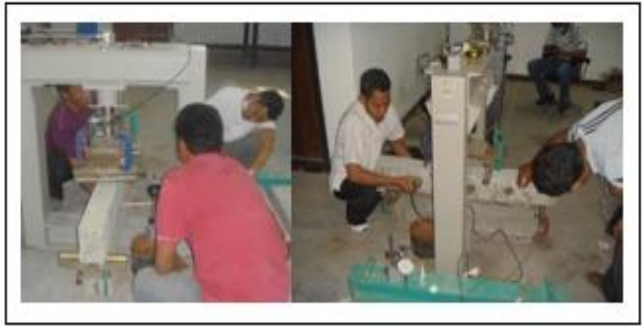

Gambar 5. Pengujian Combinasi DT dan NDT pada Balok

\section{Analisa Data}

Data pengujian kombinasi $D T$ dan $N D T$ diolah untuk membangun model korelasi antara nilai cepat rambat gelombang $(v)$ dengan kuat tekan $\left(f^{\prime} c\right)$ pada beton, Korelasi antara nilai pantul $(R)$ dengan $f^{\prime} c$ pada beton, korelasi antara modulus dinamis (Ed) dengan $f^{\prime} c$, dan membangun model korelasi antara $E d$ dengan modulus dinamis $(E c)$.

Model korelasi antara parameter tersebut ditentukan dengan menggunakan analisa korelasi dengan bantuan Grafik MS Office yang modelnya bergantung pada tren data yang diperoleh.

Model Korelasi yang terbangun tersebut digunakan untuk menginterpretasi kondisi atau keamanan struktur pada tinjauan kapasitas penampang (ultimate limits state) dan lendutan/defleksi (serviceability limits state) pada elemen balok beton bertulang sebagai perwakilan elemen struktur lentur di lapangan (struktur balok eksisting).

\section{HASIL DAN PEMBAHASAN Hasil pengujian sifat fisik bahan penyusun beton}

Pada penelitian ini digunakan agregat halus dan agregat kasar berasal dari Pringgabaya, Lombok Timur yang disediakan oleh PT. Utama Beton Perkasa. Berdasarkan hasil pengujian menunjukkan bahwa sifat fisik yang meliputi berat satuan agregat, gradasi 
agregat, kadar lumpur agregat halus dan berat jenis agregat memenuhi standar SNI S-04-1989F sebagai bahan campuran beton. Hasil selengkapnya pada Tabel 2 . sebagai berikut:

Tabel 2. Data Hasil Pemeriksaan Bahan Penyusun Beton
\begin{tabular}{|l|c|}
\hline Pemeriksaan Bahan & Hasil pemeriksaan bahan \\
\hline Berat satuan pasir & $1,341 \mathrm{gr} / \mathrm{cm}^{3}$ \\
a. Berat satuan lepas & $1,520 \mathrm{gr} / \mathrm{cm}^{3}$ \\
b. Berat satuan padat & \\
\hline Berat satuan batu pecah & $1,451 \mathrm{gr} / \mathrm{cm}^{3}$ \\
a. Berat satuan lepas & $1,646 \mathrm{gr} / \mathrm{cm}^{3}$ \\
b. Berat satuan padat & 3,203 \\
\hline Modulus halus butir (MHB) pasir & 6,67 \\
\hline Modulus halus butir (MHB) batu pecah & $3,06 \%$ \\
\hline Kandungan lumpur dalam pasir & 2,65 \\
\hline Berat jenis pasir, SSD & 2,56 \\
\hline Berat jenis batu pecah, SSD & \\
\hline
\end{tabular}

\section{Hubungan $v$ dengan $f^{\prime} c$}

Dari hasil penelitian diperoleh pola hubungan $f^{\prime} c$ dengan $v$ seperti ditunjukkan oleh Gambar 6. berikut:

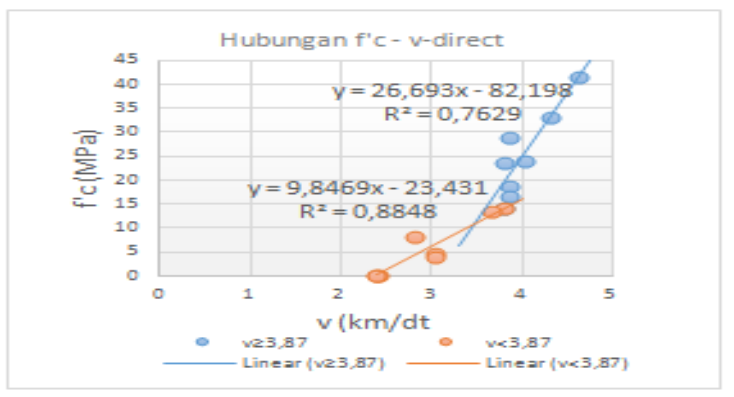

Gambar 6. Hubungan Korelasi $v$ dengan $f^{\prime} c$

Gambar 6. menunjukkan semakin besar nilai cepat rambat gelombang semakin besar pula nilai kuat tekan beton ( $\mathrm{v}$ berbanding lurus dengan f'c). Dari grafik pada Gambar 6 . Dapat dibangun dua persamaan korelasi f'c dengan v sebagai berikut:

f'cprediktif $=40,4465 \mathrm{v}$

139,84

Persamaan 1 digunakan Jika $\mathrm{v} \geq 3,8$ dan Jika $\mathrm{v}<3,8$ f'c dapat diprediksi dengan Persamaan 2. berikut ini:

$\mathrm{f}^{\prime}$ cprediktif $=8,7802 \mathrm{v}-21,398$.

\section{Hubungan Ec dan Ed}

Modulus elastisitas statis $(E c)$ didapatkan dari uji silinder yang dihitung dengan Persamaan 2, maka untuk benda uji kubus nilai $E c$ diambil sebesar $4700 \sqrt{f^{\prime}} c$.
Nilai $f^{\prime} c$ yang digunakan adalah nilai $f^{\prime} c$ kubus yang telah dikonversi ke kuat $f^{\prime} c$ silinder. Sedangkan nilai modulus elastisitas dinamis $(E d)$ dihitung dengan persamaan 2 . dimana nilai cepat rambat gelombang (v) diambil saat pembacaan pundit titik $40 \%$ tegangan maksimum.

Semakin besar nilai modulus dinamis semakin besar pulai nilai modulus statis pada beton ( $E d$ berbanding lurus dengan $E c$ ). Korelasi antara Ec dengan Ed ditunjukkan dalam Gambar 7. berikut. Hubungan antara $E c$ dengan $E d$ variasi mutu beton dapat dinyatakan dengan persamaan korelasi:

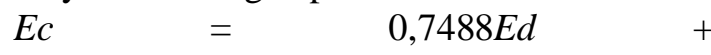

5228,9

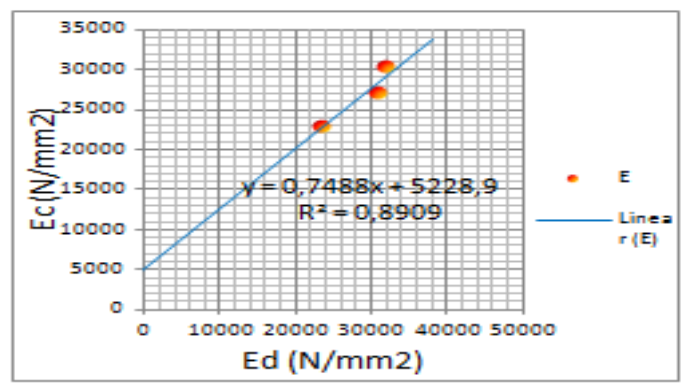

Gambar 7.Hubungan Ec dengan $E d$

Dari pengujian kubus diperoleh $f^{\prime} c$ yang telah dikonversi ke kuat $f^{\prime} c$ silinder. Sedangkan nilai modulus elastisitas dinamis $(E d)$ untuk setiap mutu beton dihitung dengan persamaan 2 . Nilai cepat rambat gelombang $(v)$ diambil saat pembacaan pundit titik $40 \%$ tegangan maksimum.

Dalam pengukuran NDT dilapangan tidak diketahui beban yang diterima konstruksi oleh karena itu perlu dibangun hubungan korelasi antara $E d$ dengan $f^{\prime} c$. Hasil Pengjian menunjukkan bahwa $E d$ berbanding lurus dengan $f^{\prime} c$ seperti ditunjukkan pada Gambar 8 dan diperoleh persamaan korelasi $f^{\prime} c$ dengan $E d$ adalah:

Ed 486,44

$f^{\prime} c+12793$ 


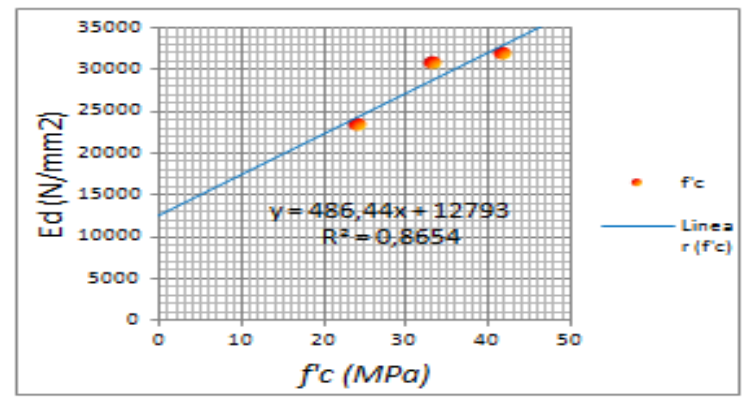

Gambar 8. Hubungan korelasi Ed dengan $f^{\prime} c$

\section{Hubungan R dengan f'c}

Semakin besar nilai pantul maka semakin besar pula nilai kuat tekan pada beton ( $R$ berbanding lurus dengan $f^{\prime} c$ ) seperti ditunjukkan Gambar 8. Hubungan korelasinya ditunjukkan dengan persamaan;

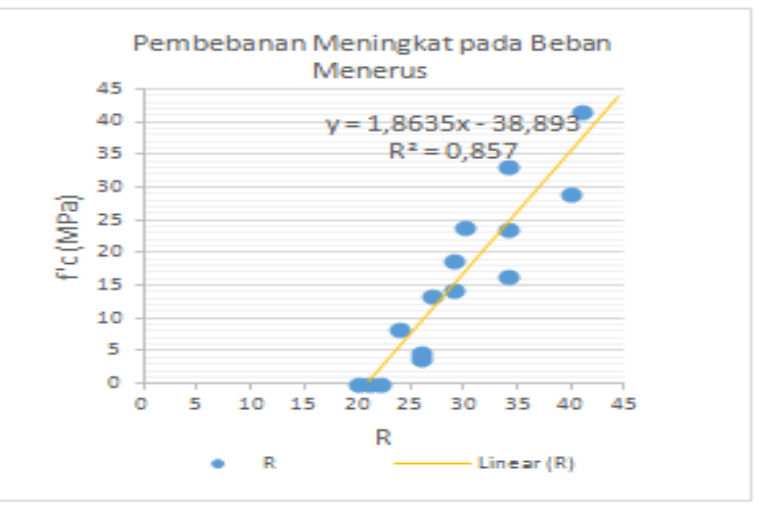

Gambar 9. Hubungan korelasi $R$ dengan $f^{\prime} c$

\section{Uji Lentur Balok}

Pengujian elemen balok bertujuan sebagai perwakilan elemen struktur balok dilapangan. Pada pengujian ini akan diaplikasikan model yang terbentuk pada pengujian utama untuk melihat kualitas balok pada setiap peningkatan beban dan tingkat keamanan elemen struktur berdasarkan Kapasitas Penampang (Ultimate Limits State) dan kontrol terhadap batas defleksi (Serveacibility Limits State) sebarapa besar rasio hasil penerapan model terhadap kondisi balok yang sebenarnya berdasarkan pembebanan sesungguhnya.

\section{Kapasitas Penampang Balok}

Tabel 4. Kapasitas Penampang Berdasarkan nilai v

\begin{tabular}{|c|c|c|c|c|c|c|}
\hline Spesimen & $v(\mathrm{~km} / \mathrm{dt})$ & $f^{\prime} c(\mathrm{MPa})$ & $\begin{array}{c}M u_{\text {prdikxif }} \\
(\mathrm{kNm})\end{array}$ & $\begin{array}{c}M u_{\text {aktual }} \\
(\mathrm{kNm})\end{array}$ & Rasio & $\begin{array}{c}\text { Rerata } \\
\text { Rasio }\end{array}$ \\
\hline B -25 & 4,032 & 25,10 & 6,407 & 7,941 & 0,807 & \multirow{3}{*}{0,983} \\
\hline B - 35 & 4,340 & 34,04 & 8,498 & 8,248 & 1,030 & \\
\hline B -45 & 4,470 & 37,82 & 9,371 & 8,433 & 1,111 & \\
\hline
\end{tabular}

Tabel 4. Kapasitas Penampang Berdasarkan nilai $\mathrm{R}$

\begin{tabular}{|c|c|c|c|c|c|c|}
\hline Spesimen & $R$ & $f^{\prime} c(\mathrm{MPa})$ & $\begin{array}{c}\text { Mupprikikif } \\
(\mathrm{kNm})\end{array}$ & $\begin{array}{c}M u_{\text {aktual }} \\
(\mathrm{kNm})\end{array}$ & Rasio & $\begin{array}{c}\text { Rerata } \\
\text { Rasio }\end{array}$ \\
\hline B - 25 & 32 & 19,82 & 5,225 & 7,941 & 0,623 & \multirow{3}{*}{0.808} \\
\hline B - 35 & 32 & 21,49 & 5,694 & 8,248 & 0,605 & \\
\hline B -45 & 40 & 33,19 & 9,064 & 8,433 & 1,075 & \\
\hline
\end{tabular}

mutu beton pada balok beton mutu 25 MPa dan $35 \mathrm{MPa}$ underestimate terhadap MUeksperimen/aktual, dan pada mutu balok beton $45 \mathrm{MPa}$ MU-prediktif overestimate terhadap MU-eksperimen/aktual. Rata-rata rasio MUprediktif terhadap MU-aktual 0,983 jika prediksi berdasarkan uji Pundit dan rata-rata rasio 0,808 jika prediksi berdasarkan uji Hammer. Artinya model yang terbangun dapat digunakan (acceptable) untuk memprediksi kapasitas elemen struktur balok dilapangan.

\section{Kontrol Defleksi Balok}

Dari pengujian pembebanan pada balok diketahui besar defleksi yang terjadi yang sesungguhnya $\left(\delta_{\text {aktual }}\right)$. Dengan pengujian NDT bisa diprediksi kuat tekan $\left(f^{\prime} c_{\text {prediktif }}\right)$ dengan menggunakan Persamaan 1., Persamaan 2., dan Persamaan 5. Kemudian dari $f^{\prime} c_{\text {prediktif }}$ diperoleh $E d$ dan $E c$ dengan Persamaan 3., dan Persamaan 4., yang nantinya menjadi dasar perhitungan defleksi teoritis $\left(\delta_{\text {teori }}\right)$ elemen balok. Defleksi teoritis dihitung dengan menggunakan rumus defleksi model pembebanan 2 titik.

Hasil penelitian pada pembebanan $0 \% \mathrm{P}$ sampai dengan $40 \%$ ditunjukkan dalam Gambar 10. Dan Gambar 11. berikut ini:

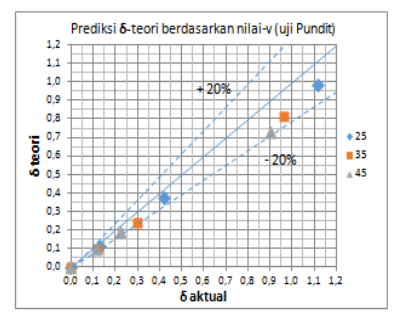

(a)

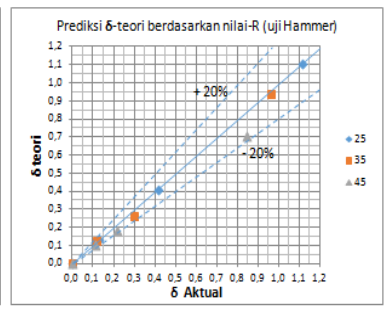

(b)
Gambar 10. Perbandingan $\delta_{\text {altual }}$ dengan $\delta_{\text {taodi }}$

Gambar 10. ini menunjukkan perbedaan defleksi teoritis dan defleksi aktual dari benda uji dimana secara umum defleksi teoritis lebih kecil 
(underestimate) dibanding defleksi aktual. Walaupun defleksi aktual dari benda uji ini belum tepat seperti yang diprediksi tetapi dari sudut pandang penggunaan model dari uji pendahuluan berdasarkan uji Pundit dan uji Hammer dalam penelitian ini dapat menghasilkan variasi nilai teoritis dimana penyebarannya (scattered) masih dalam batas yang diizinkan (acceptable). Batas akurasi yang digunakan $\pm 20 \%$ mengacu pada beberapa penelitian terdahulu (Akmaluddin \& Thomas, C.,;2006) dan (Gilbert,R.I.:1999)

\section{KESIMPULAN}

Dari hasil penelitian, pengujian, analisa data, dan pembahasan yang telah dilakukan dalam penelitian ini, dapat ditarik kesimpulan sebagai berikut:

1. Model yang terbangun dari uji laboratorium dapat digunakan (acceptable) untuk asesmen struktur balok beton bertulang.

2. Hasil prediksi $\mathrm{Mu}$ dari Uji Pundit dan Hammer underestimate terhadap $\mathrm{Mu}$ aktual dengan rasio rata-rata 0,983 berdasarkan uji Pundit dan 0,808 jika menggunakan Hammer.

3. Hasil prediksi defleksi dari Uji Pundit dan Hammer underestimate terhadap defleksi actual dengan a kurasi $\pm 20 \%$.

\section{SARAN}

1. Agregat yang digunakan dalam penelitian baik agregat halus maupun agregat kasar lebih baik dalam keadaan kering permukaan jenuh sehingga beton yang dihasilkan sesuai dengan yang direncanakan.

2. Perlu dilakukan pengembangan penelitian terkait dengan pengaruh tulangan terhadap pengujian $N D T$ pada struktur.

\section{DAFTAR PUSTAKA}

Agency, I. A. E. (2002). Guidebook o ondestructive testing of concrete structures. Training Course Series, 17.

Akmaluddin. (2008). Utilising Ndt Aparatus for Strength Assesment of Concrete Structural Element. Rekayasa, 9(2), 93-98.

Akmaluddin. \& Thomas, C.,(2006). Experimental Verification of Effective Moment of Inertia Used in the Calculation of Reinforced Concrete Beam Deflection, Proceeding of Civil Engineering Conference "Towards Suistainable Civil
Engineering Practice" ITB Journal of Engineering Science.Vol.43, No.3, 2011.227-243

Bungey J.H., Millard S. G. dan Granthan M. G. (1982). Testing of Concrete in Structures (4th ed.). 270 Madison Ave, New York, USA: Taylor \& Francis.

Dipohusodo, I. (1993). Struktur Beton Bertulang berdasarkan SKSNI T 15-1991-03. Jakarta: Departemen Pekerjaan Umum.

Gilbert, R.I, \& Thomas, C.,(1999). Deflection Calculation for Reinforced Concrete Structures-Why We Sometimes Get It Wrong, ACI Structural Journal, pp,10271032.

L.Schodek, D. (1998). Struktur. (M. S. Ir.Bambang Suryoatmono, Ed.) (3rd ed.). Cambridge, Massachusetts: Refika Aditama.

Lawson, K.A. Danso, H.C. Odoi, C.A. Adjei, F.K. Quashie, I.I. Mumuni, dan Ibrahim, I. . (2011). Non Destructive Evaluation of Concrete using Ultrasonic Pulse Velocity Research. Journal of Applied Sciences Engineering and Technology, vol.3, p. 499-504.

Lubis, M. (2003). Pengujian Struktur Beton dengan Metode Hammer Test dan Metode Uji Pembebanan (Load Test). USU Digital Library, 1-17.

Mulyono, T. (2004). Teknologi Beton. Yogyakarta: Penerbit Andi.

Nash, I. H., Hameed A.S., dan Abdullah S. A. (2005). Finding an Unified Relationship between Crushing Strength of Concrete and Non-destructive Tests.

SNI-03-2847. (2002). Tata Cara Perhitungan Struktur Beton untukBangunan Gedung. Departemen Pekerjaan Umum.

SNI-2843. (2013). Persyaratan Beton Struktural untuk Bangunan Gedung. Badan Standarisasi Nasional.

SNI-2847:2013. (2013). Persyaratan Struktural untuk Bangunan Gedung.

Turgut, P. (2010). Research into the correlation between concrete strength and UPV values. Civil Engineering, 12(12), 1-7.

Winarsih, T. (2010). Asesmen kekuatan struktur bangunan gedung. Surakarta: Universitas Sebelas Maret. 